\title{
Increased unsaturation of lipids in cytoplasmic lipid droplets in DAOY cancer cells in response to cisplatin treatment
}

\author{
Xiaoyan Pan • Martin Wilson · Carmel McConville • \\ Theodoros N. Arvanitis · Julian L. Griffin • \\ Risto A. Kauppinen · Andrew C. Peet
}

Received: 13 August 2012/Accepted: 19 November 2012/Published online: 14 December 2012

(C) The Author(s) 2012. This article is published with open access at Springerlink.com

\begin{abstract}
Increases in ${ }^{1} \mathrm{H}$ nuclear magnetic resonance spectroscopy (NMR) visible lipids are a well-documented sign of treatment response in cancers. Lipids in cytoplasmic lipid droplets (LDs) are the main contributors to the NMR lipid signals. Two human primitive neuroectodermal tumour cell lines with different sensitivities to cisplatin treatment were studied. Increases in NMR visible saturated and unsaturated lipids in cisplatin treated DAOY cells were associated with the accumulation of LDs prior to DNA fragmentation due to apoptosis. An increase in unsaturated fatty acids (UFAs) was detected in isolated LDs from DAOY cells, in contrast to a slight decrease in UFAs in lipid extracts
\end{abstract}

X. Pan · M. Wilson · C. McConville · A. C. Peet

Cancer Sciences, University of Birmingham, Birmingham, $\mathrm{NH}, \mathrm{UK}$

X. Pan - M. Wilson - A. C. Peet

Birmingham Children's Hospital NHS Foundation Trust, Birmingham, NH, UK

T. N. Arvanitis

Electronic, Electrical and Computer Engineering, University of Birmingham, Birmingham,

$\mathrm{NH}, \mathrm{UK}$

\section{J. L. Griffin}

Department of Biochemistry and the Cambridge Systems Biology Centre, University of Cambridge, Cambridge, NH, UK

\section{R. A. Kauppinen}

Clinical Research and Imaging Centre and Department of Experimental Psychology, University of Bristol, Bristol, $\mathrm{NH}, \mathrm{UK}$

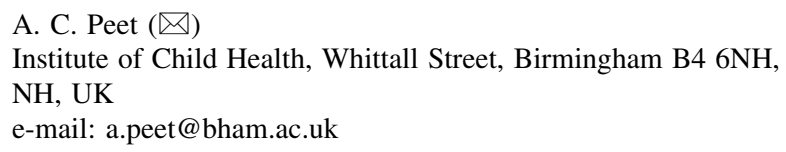

from whole cells. Oleic acid and linoleic acid were identified as the accumulating UFAs in LDs by heteronuclear single quantum coherence spectroscopy (HSQC). ${ }^{1} \mathrm{H}$ NMR lipids in non-responding PFSK-1 cells were unchanged by exposure to $10 \mu \mathrm{M}$ cisplatin. These findings support the potential of NMR detectable UFAs to serve as a non-invasive marker of tumour cell response to treatment.

Keywords Lipid droplets $\cdot{ }^{1} \mathrm{H}$ NMR · Isolation · Cisplatin

\section{Introduction}

An increase in lipids detected by ${ }^{1} \mathrm{H}$ NMR has been reported in successful treatment of brain tumours (Griffin et al. 2003; Hakumaki et al. 1999), lymphomas (Schmitz et al. 2005) and breast cancers (Musacchio et al. 2009) indicating their potential as non-invasive biomarkers in cancer management.

Studies on cancer cells in vitro (Shih et al. 2005) and in preclinical tumour models (Griffin et al. 2003) have demonstrated that apoptosis induced by anti-cancer therapies results in subtle increases in saturated aliphatic ${ }^{1} \mathrm{H}$ NMR signals as well as unsaturated bis-allylic and vinyl peaks. The increase in ${ }^{1} \mathrm{H}$ NMR lipids is closely associated with an increase in size and number of cytoplasmic lipid droplets (LDs) (Mirbahai et al. 2012), the principal source of NMR detectable lipids in vivo (Quintero et al. 2007). While some cells show an increase in the $\mathrm{CH}_{2} / \mathrm{CH}_{3}$ ratio during apoptosis, which could reflect an increase in the proportion of long chain fatty acyl moieties (Shih et al. 2005), other cell lines show no change in this ratio with treatment (Schmitz et al. 2005). Contributions to the $-\mathrm{CH}_{3}$ resonance from macromolecules rather than an increase in fatty acid chain length can explain the increased $\mathrm{CH}_{2} / \mathrm{CH}_{3}$ ratio (Mirbahai et al. 
2012) but this has not been demonstrated directly in lipid droplets. It has been proposed that NMR visible lipids accumulating during apoptosis originate from membranous cell structures due to lipolysis and repartitioning (Griffin et al. 2003). However, a recent cell study concluded that de novo lipid synthesis may also contribute to the accumulation of ${ }^{1} \mathrm{H}$ NMR lipid signals (Boren and Brindle 2012).

We have recently reported that lipids in LDs from neuroblastoma cells contain phospholipids, triglyceride, cholesterol and cholesteryl esters with both saturated and unsaturated fatty acid chains being present (Pan et al. 2012). In the current study, two human primitive neuroectodermal tumour (PNET) cell lines were treated with cisplatin to examine lipid species in whole cells as well as in extracts from whole cell and isolated LD preparations. 1D ${ }^{1} \mathrm{H}$ NMR and 2D HSQC were used to characterise the chemical nature of lipid species in untreated and cisplatin treated cancer cells. Our hypothesis was that during cell death, more unsaturated fatty acids would be observed in the ${ }^{1} \mathrm{H}$ NMR spectra of whole cells and that this would be reflected in the composition of the isolated lipid droplets. Information on the chemical nature of lipids in LDs will help to improve our understanding of these important structures and how they alter in the cell death process.

\section{Materials and methods}

\subsection{Cell culture}

Two neuronal brain tumour cell lines: DAOY, human medulloblastoma and PFSK-1, human supratentorial primitive neuroectodermal tumour were cultured in $75 \mathrm{~cm}^{2}$ flasks with filter-vented caps and maintained in $15 \mathrm{ml}$ Dulbecco's modified eagles medium (DMEM F:12) (Invitrogen, UK) supplemented with $10 \%(\mathrm{v} / \mathrm{v})$ foetal calf serum (PAA, UK), $1 \% 200 \mathrm{mM}$ L-glutamine $(100 \times)$ and $1 \%$ non-essential amino acid solution $(100 \times)$ (Sigma, UK). Cells were incubated at $37^{\circ} \mathrm{C}$ in a humidified atmosphere $\left(5 \% \mathrm{CO}_{2}, 95 \%\right.$ air $)$.

\subsection{Cisplatin exposure}

$2 \mathrm{mM}$ stock solution was made from cisplatin powder (Sigma Aldrich, UK) with DMEM stored at $-80{ }^{\circ} \mathrm{C}$ in dark conditions. 10-100 $\mu \mathrm{M}$ cisplatin working solution was freshly made from the stock cisplatin with culture media before adding to the cell culture.

\subsection{Alamar blue assay for cell viability}

Cells were seeded in flat-bottomed IWAKI 96-well culture plates at a density of $1 \times 10^{4}$ cells/well and cultured for
$24 \mathrm{~h}$ giving a 50-70\% confluence. Cisplatin was added into each well and the plates were incubated at $37{ }^{\circ} \mathrm{C}$ and $5 \% \mathrm{CO}_{2}$ for $48 \mathrm{~h}$. Alamar blue assay to estimate number of viable cells was performed as previously described (6).

\subsection{Isolation of LDs}

A protocol developed by Weller et al. was used to isolate lipid droplets (Weller et al. 1991). Briefly, 40-60 × 106 cells were ground in $600 \mu \mathrm{l}$ deionised water or $\mathrm{D}_{2} \mathrm{O}$ using a Dounce grinder and the homogenate was centrifuged at $2000 \times g$ at $4{ }^{\circ} \mathrm{C}$ for $10 \mathrm{~min}$. The supernatant was adjusted to $18.46 \%$ sucrose, topped with the same volume of deionised water or $\mathrm{D}_{2} \mathrm{O}$ and centrifuged at $142,000 \times g$ for 120 min at $4{ }^{\circ} \mathrm{C}$ (Optima TLX Ultracentrifuge, Beckman). After ultracentrifugation, the sample was separated into three fractions, the upper isolated fraction, the middle sucrose fraction and the pellet. At least three independent preparations for each condition and cell type were used for isolation.

\subsection{Lipid extraction}

A dual-phase methanol-chloroform extraction protocol was used to prepare the lipid extracts for NMR analysis from both cells and isolated lipid droplets. $20-40 \times 10^{6}$ cells were ground and sonicated in methanol/deionised water. $200 \mu \mathrm{l}$ chloroform was added to the homogenates twice to form a dual-phase. For isolated LDs, methanol and chloroform was added directly into the isolated fraction. At least three independent preparations from each condition and cell type were used for extraction.

\subsection{Nile red and DAPI staining}

Cells were spun onto slides and stained with $4 \mu \mathrm{g} / \mathrm{ml}$ Nile red, a dye staining for lipid droplets, in phosphate buffered saline (PBS, made from $1 \mathrm{mg} / \mathrm{ml}$ Nile red stock solution in acetone, Sigma Aldrich, Dorset, UK) for about $15 \mathrm{~min}$ under dark conditions. After Nile red staining, cells were stained with $0.4 \mu \mathrm{g} / \mathrm{ml}$ DAPI, a dye staining for cell nuclei, for $15 \mathrm{~min} .5 \mu \mathrm{l}$ isolated fraction were dropped on to an ethanol and deionised water washed slide and stained with $4 \mu \mathrm{g} / \mathrm{ml} \mathrm{Nile} \mathrm{red} \mathrm{in} 70 \%$ ethanol for $15 \mathrm{~min}$. The slides were visualized with a Nikon Eclipse E600 microscope and images were taken using a DXM1200 digital camera. The green fluorescence of Nile red was observed with FITC (B2A) filter set, with excitation wave length of 465-495 nm and emission wave length of $550 \mathrm{~nm}$. LD sizes were measured using the image analysis software Image $\mathbf{J}$ (National Institute of Health, USA). DAPI UV (UV-2A) filter with excitation wavelength of 340-380 nm was used to detect DAPI stained nuclei. 


\subsection{HR-MAS}

Prior to HR-MAS, frozen cells in PBS were defrosted, and $45 \mu \mathrm{L}$ of suspension containing approximately $10 \times 10^{6}$ cells was pipetted into a $50 \mu \mathrm{L}$ rotor (Bruker, Karlsruhe, Germany); $5 \mu \mathrm{L} 50 \mathrm{mmol} / \mathrm{L}$ trimethylsilylproprionate $\mathrm{d} 4$ (TMS) in D2O was added as a chemical shift standard. HRMAS was performed on a Bruker $500 \mathrm{MHz}$ spectrometer using a HR-MAS probe (Bruker, Karlsruhe, Germany). The probe temperature was set to $278 \mathrm{~K}$ to minimize the degradation. The rotor speed was $4,800 \mathrm{~Hz}$ in all experiments. The pulse sequence consisted of a single $90^{\circ}$ pulse with one second water presaturation pulse. The receiver bandwidth was $7,200 \mathrm{~Hz}$ covered with $16 \mathrm{~K}$ complex points. A total of 256 scans were acquired with a repetition time of $3.3 \mathrm{~s}$.

\subsection{Liquid-state ${ }^{1} \mathrm{H}$ NMR spectroscopy}

Lipid extracts were resuspended in $600 \mu \mathrm{l}$ deuterated chloroform containing $0.03 \%$ (v/v) TMS (Sigma Aldrich, Dorset, UK). ${ }^{1} \mathrm{H}$ NMR spectra of cell extracts and the isolated LDs suspended in $\mathrm{D}_{2} \mathrm{O}$ were recorded on a Varian $600 \mathrm{MHz}$ vertical bore spectrometer using a triple-resonance $\mathrm{HCN}$ probe. A standard pulse-acquire sequence was used as above for HR-MAS.

\subsection{HSQC}

A phase-sensitive gradient enhanced $2 \mathrm{D}{ }^{1} \mathrm{H}-{ }^{13} \mathrm{C}$ HSQC was performed on whole cell pellets of DAOY cells $s$ on a Bruker DRX $500 \mathrm{MHz}$ spectrometers using the HR-MAS probe at $278 \mathrm{~K}$. 1,024 points were acquired in F2 for 256 increments in F1 with spectral widths of 13 and $166 \mathrm{ppm}$ respectively. 96 averages were performed resulting in a total experiment time of approximately $11.6 \mathrm{~h}$. Data were zero-filled to twice the original length and multiplied by a sine function prior to 2D Fourier transformation. Three independent cell samples were used for HSQC experiment.

\subsection{Spectral analysis}

The HR-MAS spectra were manually phased and referenced to creatine (3.03 ppm). Baseline correction ( $\mathrm{Xi}$ and Rocke 2008) was performed and spectra were normalized to the total intensity of the spectral region from 0.5 to $4.5 \mathrm{ppm}$ using in house software written in R. The signal intensity of the lipid peaks around $0.9,1.3,2.8,5.4 \mathrm{ppm}$ and the macromolecular peak at $1.68 \mathrm{ppm}$ were measured using peak integration to estimate the relative abundance of lipid and macromolecule. Values shown are mean \pm SD.

For extracts, the spectra were manually phased, then referenced to TMS $(0 \mathrm{ppm})$. The extract spectra were baseline corrected with spectral analysis software, wxNUTs (Acorn NMR Ltd, Canada). The lipid signal intensities were determined using the line fitting function provided by wxNUTs which fits a series of peaks to the experimental spectrum and determines the signal intensity from the fit. Student's $t$ test was performed on the treated versus untreated cell data.

The HSQC spectra were manually phased, referenced to TMS peak at $0 \mathrm{ppm}$ and integrated with Topspin 3.0 software (Bruker, Germany).

\section{Results}

The Alamar blue assay showed that with a $48 \mathrm{~h}$ exposure to $10 \mu \mathrm{M}$ cisplatin, $5 \pm 0.2 \%$ of DAOY cells were viable while around $60 \pm 1.1 \%$ of PFSK-1 cells were still viable. DAOY showed a clear response to $10 \mu \mathrm{M}$ cisplatin, whereas PFSK-1 did not. Thus, because of the discrimination, this concentration with a $48 \mathrm{~h}$ exposure time was chosen for subsequent experiments.

Figure 1 shows the HR-MAS spectra of DAOY cells treated with cisplatin, the spectra were scaled to the height of the macromolecule peak at $1.68 \mathrm{ppm}$ for display. For quantification, the lipid signal intensities were taken as a ratio to the macromolecule peak area at $1.68 \mathrm{ppm}$ as referencing to protein signal has been shown to be a good approach in NMR signal quantification (Bayet-Robert et al. 2010) and renders the data from different cell lines comparable.

Lipid signal intensities in HR-MAS spectra of DAOY and PFSK- 1 cells, as a function of cisplatin exposure times, are shown in Fig. 2. In DAOY cells, the signals at 0.9, 1.3, 2.8 and $5.4 \mathrm{ppm}$ start to increase by $24 \mathrm{~h}$ and continue to increase with further treatment to $48 \mathrm{~h}$. In PFSK-1 no change in ${ }^{1} \mathrm{H}$ NMR lipid peaks was detected.

Figure 3a shows ${ }^{1} \mathrm{H}$ NMR spectra of lipid species in extracts from isolated LDs following cisplatin treatment of DAOY cells. For comparison, Fig. $3 \mathrm{~b}$ shows the ${ }^{1} \mathrm{H}$ NMR spectra of lipid species in extracts from whole DAOY cells following cisplatin treatment. The spectra over the range $1-5 \mathrm{ppm}$ in Fig. $3 \mathrm{a}, \mathrm{b}$ are scaled to give the same intensity of the $\mathrm{CH}_{3}$ resonance. An expansion of the $5.35 \mathrm{ppm}$ and $1.25-1.35 \mathrm{ppm}$ regions is provided to show the increase of $\mathrm{CH}=\mathrm{CH}$ and $-\mathrm{CH}_{2}$ signal (arrows in Fig. 3a) from unsaturated lipids. For each expanded region, the intensity of the spectra has also been increased by the same arbitrary factor for all time points in order for them to be large enough to appreciate the differences in intensity within a time series. The fitting of the spectral region containing the $\mathrm{CH}_{3}$ resonance is shown in Fig. 3c.

Quantification of the ${ }^{1} \mathrm{H}$ NMR spectra acquired from lipid extracts showed that there was a statistically significant increase in the $\mathrm{CH}=\mathrm{CH} / \mathrm{CH}_{3}$ ratio in lipids in $\mathrm{LDs}$ 
Fig. 1 HR-MAS spectra of DAOY (a) and PFSK-1(b) cells treated with $10 \mu \mathrm{M}$ cisplatin at 0, 12, 24 and $48 \mathrm{~h}$. Assignments are as follows: $1 \mathrm{CH}_{3}$ at $0.9 \mathrm{ppm}, 2 \mathrm{CH}_{2}$ at $1.2-1.3 \mathrm{ppm}$, $3 \mathrm{CH}_{2} \mathrm{CH}_{2} \mathrm{CO}$ at $1.6 \mathrm{ppm}, 4$ $\mathrm{CH}_{2} \mathrm{CH}=\mathrm{CH}$ at $2.0 \mathrm{ppm}, 5$ $\mathrm{CH}_{2} \mathrm{COO}$ at $2.3 \mathrm{ppm}$, $6=\mathrm{CHCH}_{2} \mathrm{CH}=$ at $2.8 \mathrm{ppm}$, $7 \mathrm{~N}\left(\mathrm{CH}_{3}\right)_{3}$ at $3.3-3.4 \mathrm{ppm}, 8$ $\mathbf{H C}=\mathrm{CH}(\mathrm{L}, \mathrm{Ch})$ at $5.4 \mathrm{ppm}$

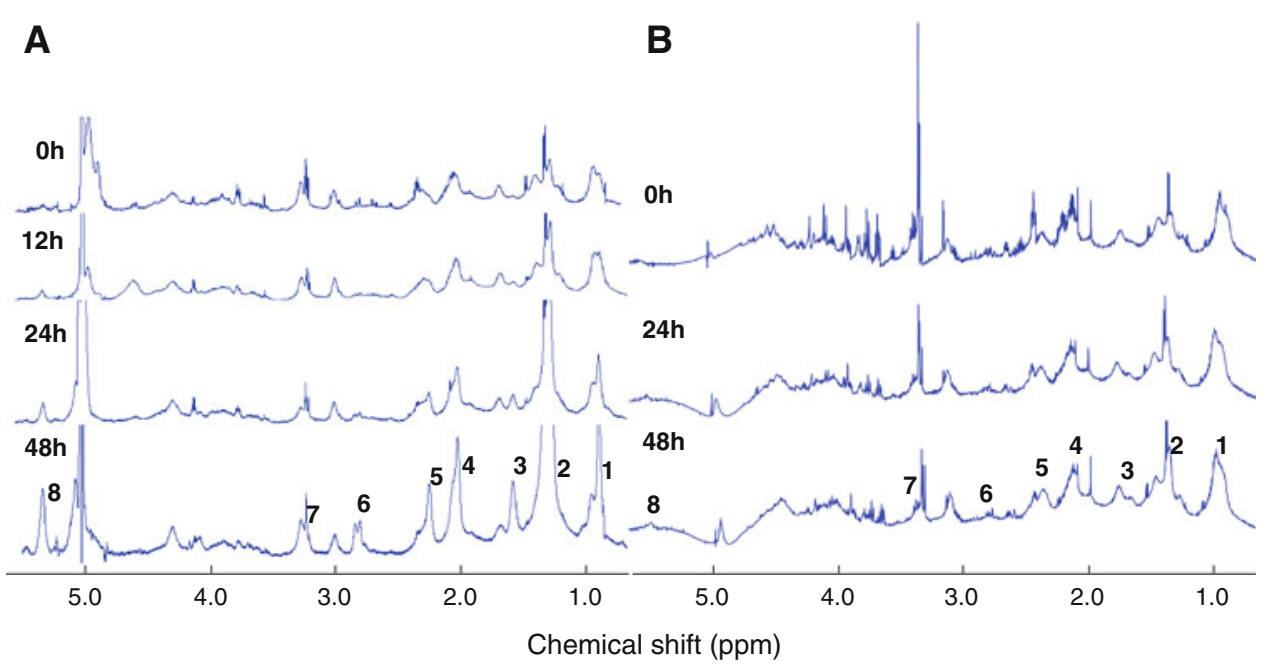

Fig. 2 Lipid signal intensity of lipid peaks at $0.9,1.3,2.8$, $5.4 \mathrm{ppm}$ of DAOY and PFSK-1 cells with or without $10 \mu \mathrm{M}$ cisplatin exposure. Values were obtained from HR-MAS spectra of intact cells
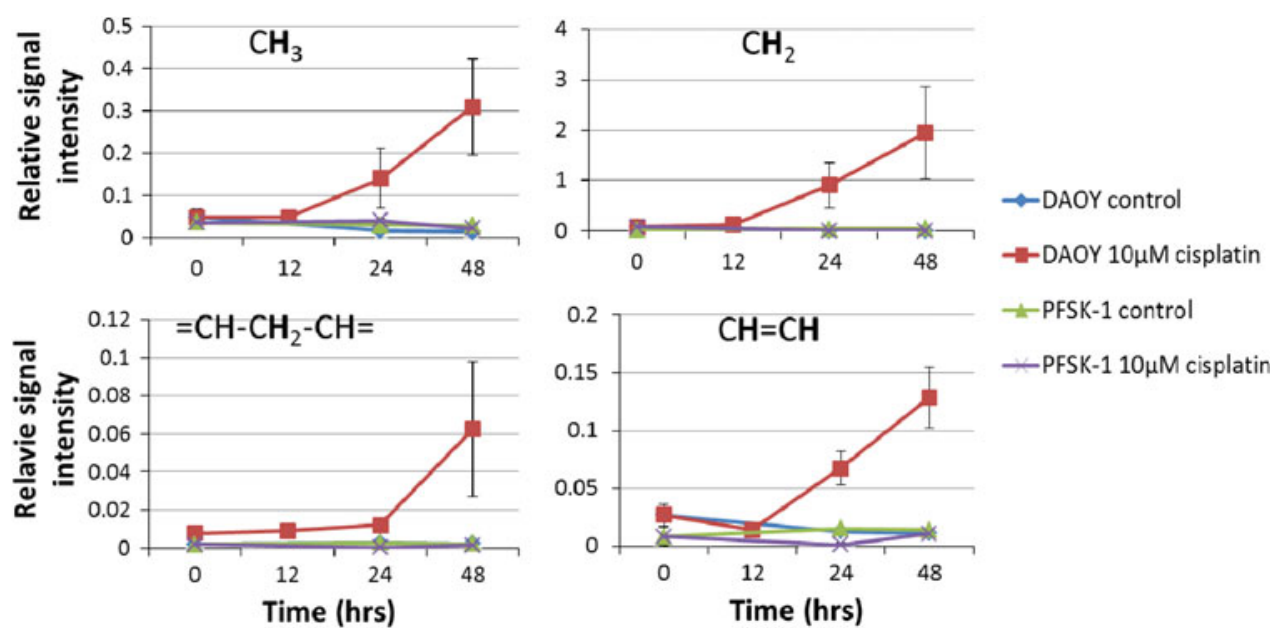

from cisplatin treated DAOY cells (Fig. 4). No such change was observed in LDs from PFSK-1 (Fig. 4). In whole cell lipid extracts, the $\mathrm{CH}_{2} / \mathrm{CH}_{3}$ and $\mathrm{CH}=\mathrm{CH} / \mathrm{CH}_{3}$ ratios remained unchanged by treatment for both cell lines, the apparent decrease in the DAOY cell line was not statistically significant. One should note that in untreated DAOY cells the ratio of $\mathrm{CH}=\mathrm{CH} / \mathrm{CH}_{3}$ of $\mathrm{LD}$ lipids was much lower than in PFSK-1, possibly due to inherent properties of the cell types, but these ratios were similar in lipids extracted from whole cells (including membrane associated lipids as well as lipid droplets).

The HSQC $\left({ }^{1} \mathrm{H}\right.$ and $\left.{ }^{13} \mathrm{C}\right)$ spectrum acquired from $48 \mathrm{~h}$ cisplatin treated DAOY cells is shown in Fig. 5. The chemical nature of unsaturated lipids is of special interest (Griffin et al. 2003; Pan et al. 2012) but cannot be determined specifically from the 1D NMR spectra. The double bond protons of unsaturated fatty acids resonating at $5.4 \mathrm{ppm}$ region in the $1 \mathrm{D}$ spectra were separated into two distinguishable signals by the 2D HSQC assigned to oleic (18:1) and linoleic acid (18:2) (Pan et al. 2012). The double bond protons in linoleic acid give two signals with an equal intensity at the $5.4 \mathrm{ppm}$ making it possible to estimate the ratio of these two unsaturated fatty acids. An oleic-to-linoleic acid ratio was found to be 1:0.89 in cisplatin treated DAOY cells.

LDs are visualised as green vesicles in Nile red stained cells, while cell nuclei stained with DAPI appear blue (Fig. 6). There was an increase in the number of small LDs (approximate diameter of $0.2 \mu \mathrm{m}$ ) by $12 \mathrm{~h}$ of $10 \mu \mathrm{M}$ cisplatin treatment in DAOY cells, while nuclei remained intact, with a diameter around 15-20 $\mu \mathrm{m}$. A ring-like arrangement of small LDs was evident in DAOY cells when the LD size increased by $24 \mathrm{~h}$ of cisplatin treatment. After $48 \mathrm{~h}$ treatment, large LDs were seen with concomitant fragmentation of nuclei. The average diameter of LDs of $0.18 \pm 0.06 \mu \mathrm{m}$ in untreated DAOY cells remained unchanged until $24 \mathrm{~h}$ of cisplatin exposure, but it had increased to $0.34 \pm 0.19 \mu \mathrm{m}$ by $48 \mathrm{~h}(P<0.001$ Student $t$ test). There was no change in either the number or the size of LDs in PFSK-1 cells exposed to $10 \mu \mathrm{M}$ cisplatin, similar to untreated DAOY cells. 
Fig. $3{ }^{1} \mathrm{H}$ NMR spectra of lipid extracts from a isolated LDs of DAOY cells and $\mathbf{b}$ whole DAOY cells treated with $10 \mu \mathrm{M}$ cisplatin at 0,24 and $48 \mathrm{~h}$. The spectra are scaled such that the $\mathrm{CH}_{3}$ triplet is the same intensity. Assignments are as follows: 1 $\mathrm{CH}_{3}$ at $0.9 \mathrm{ppm}, 2 \mathrm{CH}_{2}$ at 1.2-1.3 ppm, $3 \mathbf{H C}=\mathrm{CH}(\mathrm{L}, \mathrm{Ch})$ at $5.4 \mathrm{ppm}$. To the right is the $5.4 \mathrm{ppm}$ region and $1.3 \mathrm{ppm}$ region expanded to show the lipid signal from $\mathbf{H C}=\mathbf{C H}$ and $\mathrm{CH}_{2}$ (indicated by arrows), respectively. The intensities of these peaks have been increased by the same arbitrary factor for all timepoints. (c): Line fit for the $-\mathrm{CH}_{3}$ triplet (labelled as 1,2 and 3) signal at $0.9 \mathrm{ppm}$

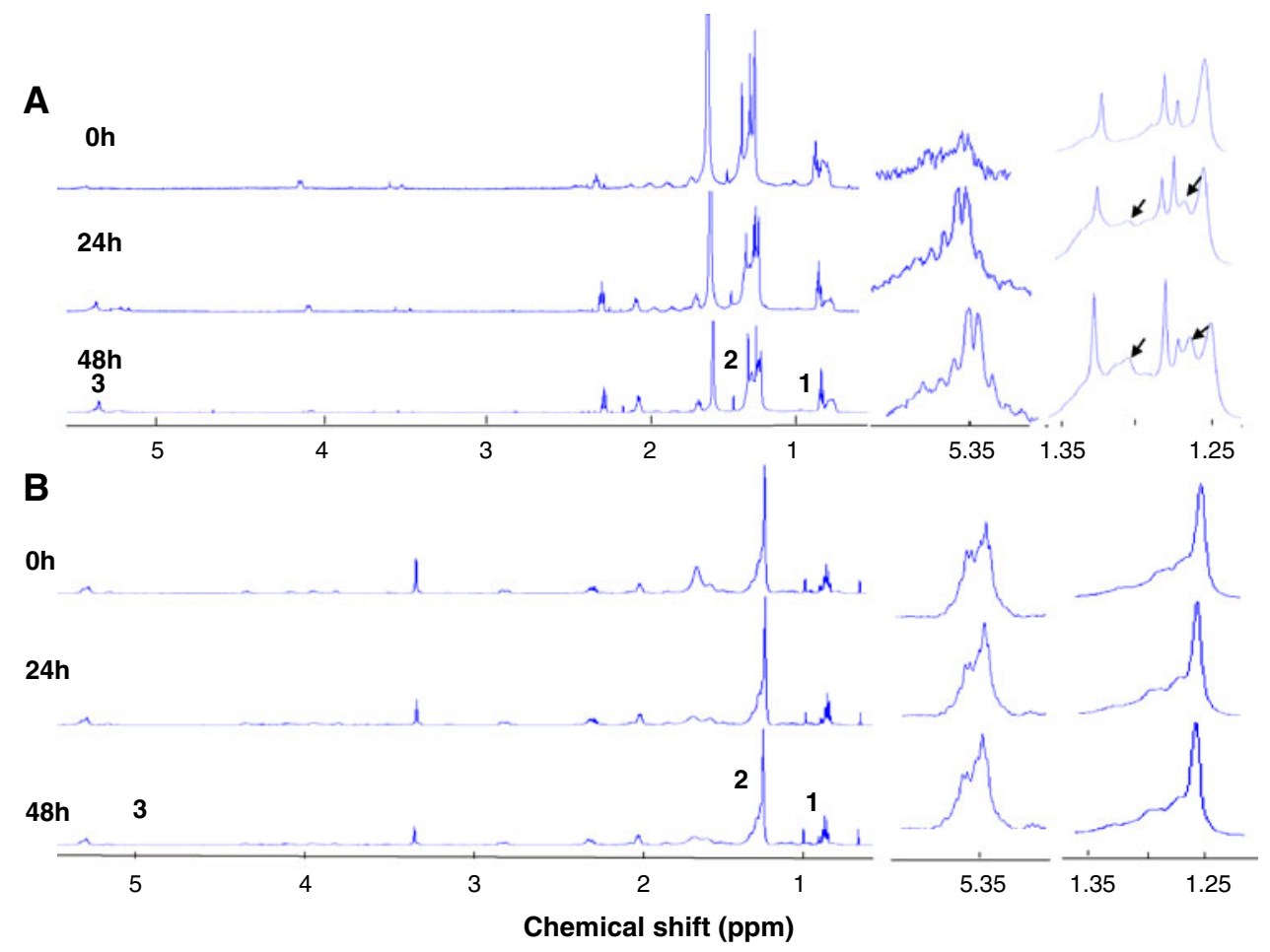

C

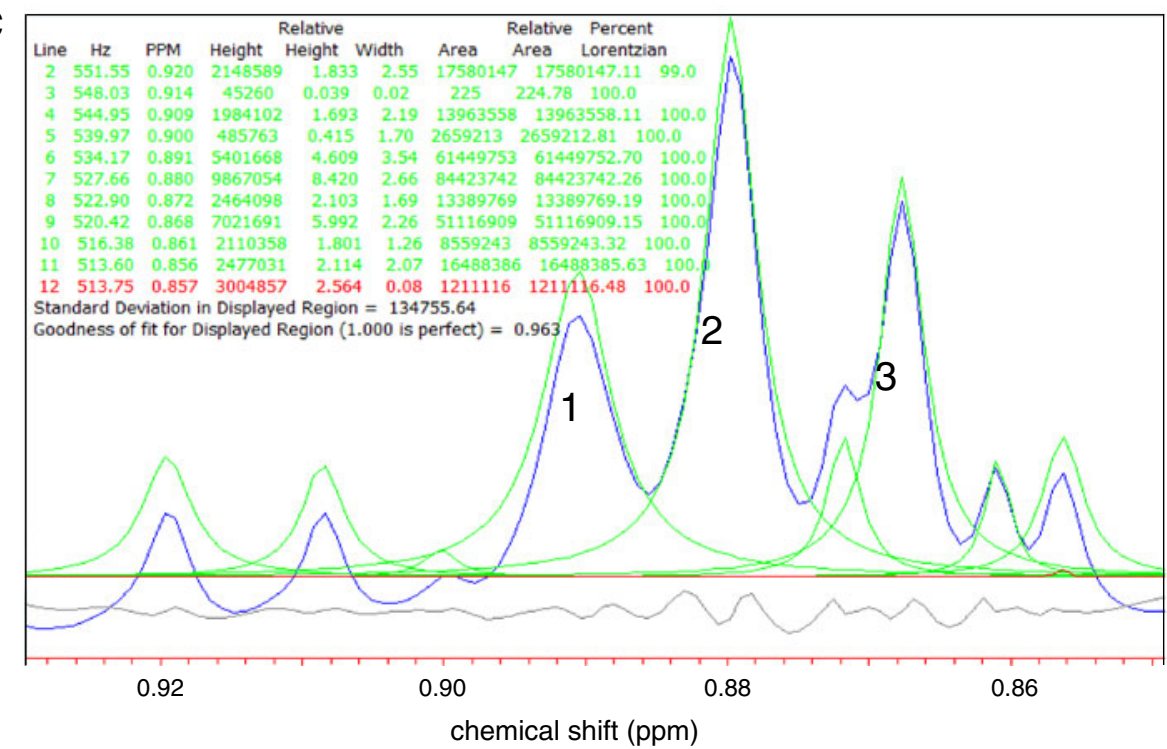

$\mathrm{CH}=\mathrm{CH} / \mathrm{CH}_{3}$

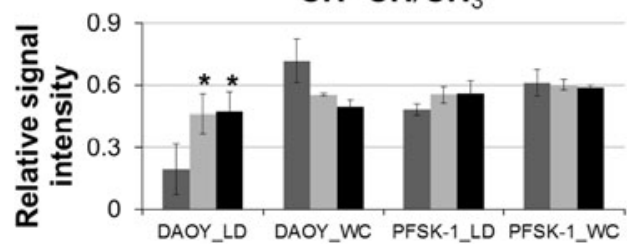

$\mathrm{CH}_{2} / \mathrm{CH}_{3}$

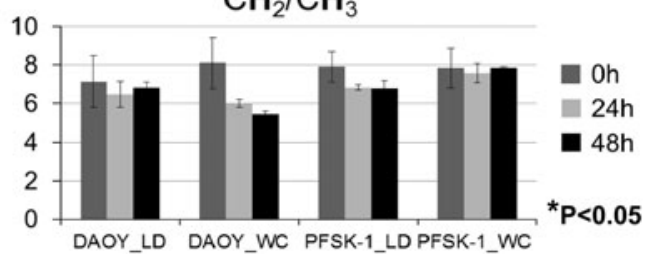

Fig. 4 Double bond proton signal/methyl group proton signal $\left(\mathrm{CH}=\mathrm{CH} / \mathrm{CH}_{3}\right)$ and methylene group proton signal/methyl group proton signal $\left(\mathrm{CH}_{2} / \mathrm{CH}_{3}\right)$ from LD lipids and whole cell (WC) lipids of DAOY and PFSK-1 cell extract spectra 
Fig. 5 HSQC spectra of $48 \mathrm{~h}$ $10 \mu \mathrm{M}$ cisplatin treated DAOY a whole spectrum from 0 to $6 \mathrm{ppm}\left({ }^{1} \mathrm{H}\right)$ and 0 to $140 \mathrm{ppm}$ $\left({ }^{13} \mathrm{C}\right)$, b expanded 5.44 to $5.35 \mathrm{ppm}$ region of the spectrum
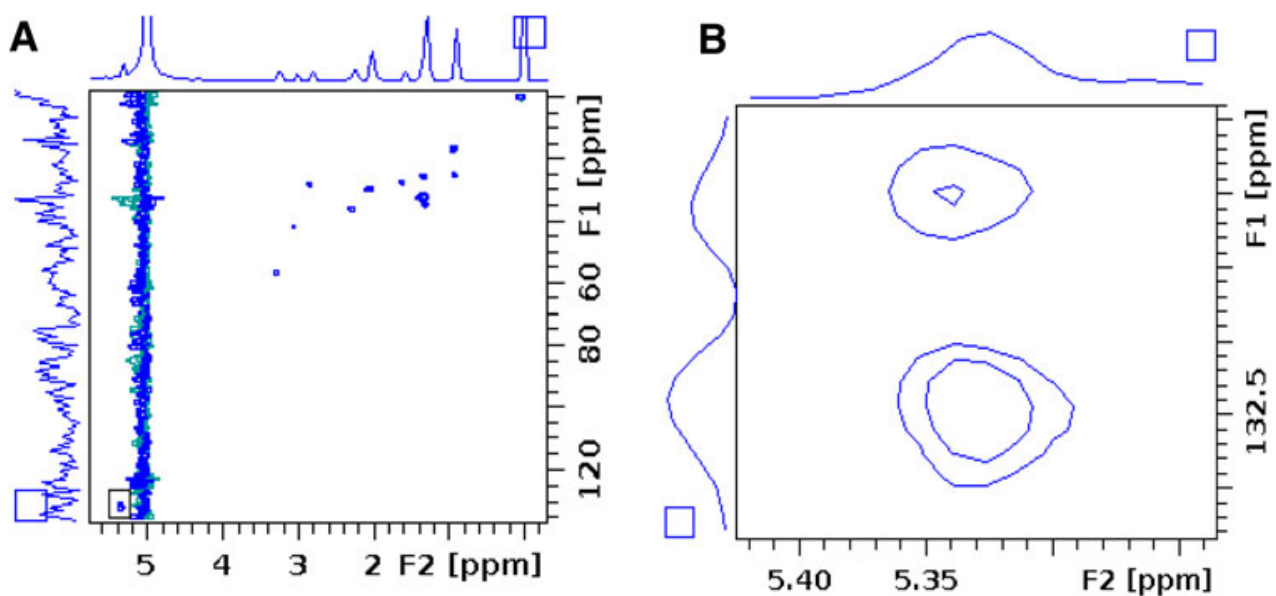
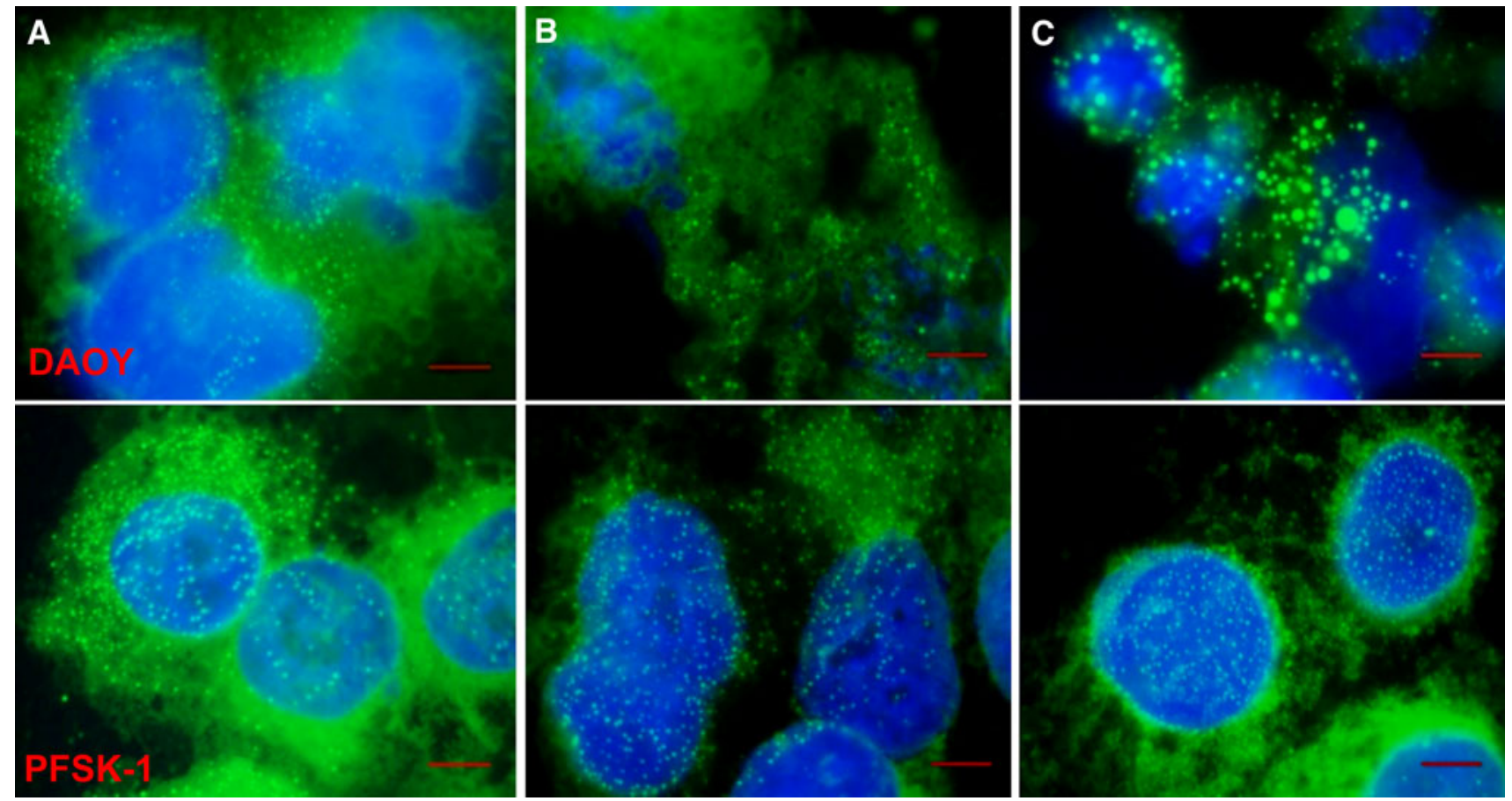

Fig. 6 Combined Nile red and DAPI staining of DAOY (upper) and PFSK-1 (lower): a untreated cells at 0 h, b $10 \mu \mathrm{M}$ cisplatin 24 h, c $10 \mu \mathrm{M}$ cisplatin $48 \mathrm{~h}$. The size bar is $5 \mu \mathrm{m}$

\section{Discussion}

The current study shows that unsaturated fatty acids detected by HR-MAS increase in whole DAOY cells undergoing cisplatin-induced cell death, consistent with studies on a glial tumour (Hakumaki et al. 1999) and lymphoma cells (Schmitz et al. 2005). Extracts of LDs show an increase in unsaturated fatty acids which reflect those seen in HR-MAS of whole DAOY cells undergoing apoptosis consistent with the ${ }^{1} \mathrm{H}$ NMR signal arising from the lipids pool present in LDs. The latter observation is in agreement with previous cell (Quintero et al. 2007; Zietkowski et al. 2012) and brain tumour (Griffin et al.
2003; Hakumaki et al. 1999) studies. These changes in lipid composition are not detected in lipid extracts from whole cells showing that the lipids from non-LD sources (such as membranes) dilute observations from a specific pool of ${ }^{1} \mathrm{H}$ NMR visible species. It was recently shown that apoptosis in EL4 lymphoma cells is accompanied with increased incorporation of external oleate into triacylglycerols (Boren and Brindle 2012). Considering the ratio of oleic-to-linoleic acid in LDs from cisplatin treated DAOY cells, it is possible that increase in unsaturation can be ascribed to excessive accumulation of linoleic acid and its incorporation into triacylglycerols. Two mechanisms have been proposed to contribute to the increased unsaturated ${ }^{1} \mathrm{H}$ 
NMR detectable lipids in apoptotic cells: (a) repartitioning from the cellular membrane degradation (Griffin et al. 2003) and (b) de novo synthesis of lipids. (Boren and Brindle 2012; Zietkowski et al. 2012).

Cisplatin as a chemotherapy drug has been used to treat various types of cancers including childhood medulloblastoma (Jakacki et al. 2012; Kim et al. 2012; Shulman et al. 2012). It causes crosslinking of DNA, which leads to tumour cell apoptosis (Tanida et al. 2012). Here DAOY cells derived from childhood medulloblastoma show greater sensitivity to cisplatin treatment than PFSK-1 cells. Cellular nuclear fragmentation of treated DAOY cells was observed as a sign of DNA damage.

LD accumulation is a common feature frequently observed in tumour cells (Delikatny et al. 2002) and tissues (Opstad et al. 2008) undergoing apoptosis and necrosis. DAOY and PFSK-1 are both primitive neuroectodermal tumour cell lines possessing a similar number and size of LDs without treatment. LDs accumulate in DAOY cells undergoing apoptosis and LDs up to $1.67 \mu \mathrm{m}$ in diameter were detected after $48 \mathrm{~h}$ cisplatin treatment. No obvious increase in LD size was observed in PFSK-1 cells with intact nuclei (Fig. 6). The increase of unsaturated fatty acids (UFAs) detected by ${ }^{1} \mathrm{H}$ NMR in treated DAOY cells was not observed in PFSK-1 cells. These observations imply that UFAs accumulate in LDs in response to treatment. We observed greater number of small LDs in DAOY cells at $12 \mathrm{~h}$ of cisplatin exposure, but this increase was not large enough to result in increase in ${ }^{1} \mathrm{H}$ NMR detected lipids in HR-MAS spectra most likely due to the fact that increase in overall volume of NMR detectable lipids was below the limit of detection. At later stages of apoptosis large LDs appear, possibly reflecting shunting of lipids released through lysosomal processing of lipids from damaged cell membranes and organelles (Delikatny et al. 2002). A recent study by Boren and Brindle on lymphoma cells treated with etoposide showed that $\beta$-oxidation becomes inhibited early on in apoptosis leading to increased de novo synthesis of lipids and accumulation of LDs. Among UFAs, PUFAs are thought to be naturally occurring anti-cancer agents (Cockbain et al. 2012). In human glioma, PUFA may stimulate tumour regression and apoptosis (Scheim 2009) and has been introduced to cancer therapy (Bakshi et al. 2003). It is not known yet whether any of these lipid-based approaches to cancer therapy will show selectivity for malignant cells, but PUFA supplementation may potentiate some anti-cancer treatment strategies (Burns and Spector 1994). Enrichment with PUFAs makes cancer cells more susceptible to lipid peroxidation and more sensitive to drug treatment (Burns and Spector 1994). In addition, the immune response in cancer can be improved by manipulating the lipid levels in dendritic cells (Herber et al. 2010). Therefore, accumulated
PUFAs after cisplatin exposure may not only be end products of cell collapse but they may also serve as functional lipid mediators actively involved in the cell death pathway.

\section{Concluding remarks}

HR-MRS of whole DAOY cells detects an increase in lipids and the proportion of these lipids which are unsaturated during treatment with cisplatin. These changes are associated with an increase in the number of cytoplasmic LDs and these droplets contain a greater proportion of unsaturated lipids than in untreated cells. An increase in the proportion of unsaturated fatty acids is not seen in the lipids extracted from whole cells during treatment. Our data argue that it is pivotal to pay attention to the degree of lipid unsaturation when considering ${ }^{1} \mathrm{H}$ MRS in monitoring treatment response.

Acknowledgments ${ }^{1} \mathrm{H}$ NMR experiments were carried out in the Henry Wellcome Building for Biomolecular NMR Spectroscopy at the University of Birmingham and we are grateful for the support of the staff at this facility. The work was partly funded by the Medical Research Council, UK (Grant G0601327), the Andrew McCartney Trust Fund for Brain Tumour Research, Birmingham Children's Hospital Research Foundation and the Brain and Nervous System Tumour Research Fund.

Open Access This article is distributed under the terms of the Creative Commons Attribution License which permits any use, distribution, and reproduction in any medium, provided the original author(s) and the source are credited.

\section{References}

Bakshi, A., Mukherjee, D., Bakshi, A., Banerji, A. K., \& Das, U. N. (2003). $\gamma$-Linolenic acid therapy of human gliomas. Nutrition, 19, 305-309. doi:10.1016/s0899-9007(02)00862-6.

Bayet-Robert, M., et al. (2010). Quantitative two-dimensional HRMAS 1H-NMR spectroscopy-based metabolite profiling of human cancer cell lines and response to chemotherapy. Magnetic Resonance in Medicine, 63, 1172-1183. doi:10.1002/mrm.22303.

Boren, J., \& Brindle, K. M. (2012). Apoptosis-induced mitochondrial dysfunction causes cytoplasmic lipid droplet formation. Cell Death and Differentiation, doi:10.1038/cdd.2012.34.

Burns, C. P., \& Spector, A. A. (1994). Biochemical effects of lipids on cancer therapy. The Journal of Nutritional Biochemistry, 5, 114-123.

Cockbain, A. J., Toogood, G. J., \& Hull, M. A. (2012). Omega-3 polyunsaturated fatty acids for the treatment and prevention of colorectal cancer. Gut, 61, 135-149. doi:10.1136/gut.2010. 233718.

Delikatny, E. J., Cooper, W. A., Brammah, S., Sathasivam, N., \& Rideout, D. C. (2002). Nuclear magnetic resonance-visible lipids induced by cationic lipophilic chemotherapeutic agents are accompanied by increased lipid droplet formation and damaged mitochondria. Cancer Research, 62, 1394-1400. 
Griffin, J. L., et al. (2003). Assignment of $1 \mathrm{H}$ nuclear magnetic resonance visible polyunsaturated fatty acids in BT4C gliomas undergoing ganciclovir-thymidine kinase gene therapy-induced programmed cell death. Cancer Research, 63, 3195-3201.

Hakumaki, J. M., Poptani, H., Sandmair, A. M., Yla-Herttuala, S., \& Kauppinen, R. A. (1999). 1H MRS detects polyunsaturated fatty acid accumulation during gene therapy of glioma: Implications for the in vivo detection of apoptosis. Nature Medicine, 5, 1323-1327. doi:10.1038/15279.

Herber, D. L., et al. (2010). Lipid accumulation and dendritic cell dysfunction in cancer. Nature Medicine, 16, 880-886.

Jakacki, R. I., et al. (2012). Outcome of children with metastatic medulloblastoma treated with carboplatin during craniospinal radiotherapy: A children's oncology group phase I/II study. Journal of Clinical Oncology. doi:10.1200/JCO.2011.40.2792.

Kim, H. J., et al. (2012). Phase II study of palliative S-1 in combination with cisplatin as second-line chemotherapy for gemcitabine-refractory pancreatic cancer patients. Oncology Letters, 3, 1314-1318. doi:10.3892/ol.2012.637.

Mirbahai, L., et al. (2012). Lipid biomarkers of glioma cell growth arrest and cell death detected by $1 \mathrm{H}$ magic angle spinning MRS. NMR in Biomedicine. doi:10.1002/nbm.2796.

Musacchio, T., Toniutti, M., Kautz, R., \& Torchilin, V. P. (2009). 1H NMR detection of mobile lipids as a marker for apoptosis: The case of anticancer drug-loaded liposomes and polymeric micelles. Molecular Pharmaceutics, 6, 1876-1882. doi:10.1021/ mp900164n.

Opstad, K. S., Bell, B. A., Griffiths, J. R., \& Howe, F. A. (2008). An investigation of human brain tumour lipids by high-resolution magic angle spinning $1 \mathrm{H}$ MRS and histological analysis. NMR in Biomedicine, 21, 677-685.

Pan, X., et al. (2012). The lipid composition of isolated cytoplasmic lipid droplets from a human cancer cell line, BE(2)M17. Molecular BioSystems, 8, 1694-1700. doi:10.1039/C2MB05485J.

Quintero, M., Cabanas, M. E., \& Arus, C. (2007). A possible cellular explanation for the NMR-visible mobile lipid (ML) changes in cultured C6 glioma cells with growth. BBA-Biochimica et Biophysica Acta, 1771, 31-44.

Scheim, D. E. (2009). Cytotoxicity of unsaturated fatty acids in fresh human tumor explants: Concentration thresholds and implications for clinical efficacy. Lipids in Health and Disease, 8, 54.

Schmitz, J. E., Kettunen, M. I., Hu, D. E., \& Brindle, K. M. (2005). $1 \mathrm{H}$ MRS-visible lipids accumulate during apoptosis of lymphoma cells in vitro and in vivo. Magnetic Resonance in Medicine, 54, 43-50.

Shih, C. M., et al. (2005). Detection of apoptosis and necrosis in normal human lung cells using 1H NMR spectroscopy. Annals of the New York Academy of Sciences, 1042, 488-496. doi:10.1196/ annals.1338.042.

Shulman, K., Haim, N., Wollner, M., Bernstein, Z., Abdah-Bortnyak, R., \& Bar-Sela, G. (2012). Postoperative chemotherapy in gastric cancer, consisting of etoposide, doxorubicin and cisplatin, followed by radiotherapy with concomitant cisplatin: A feasibility study. Oncology Letters, 3, 1154-1158. doi:10.3892/ol. 2012.617.

Tanida, S., et al. (2012). Mechanisms of cisplatin-induced apoptosis and of cisplatin sensitivity: Potential of BIN1 to act as a potent predictor of cisplatin sensitivity in gastric cancer treatment. International Journal of Surgical Oncology, 2012, 862879. doi: $10.1155 / 2012 / 862879$.

Weller, P. F., Ryeom, S. W., Picard, S. T., Ackerman, S. J., \& Dvorak, A. M. (1991). Cytoplasmic lipid bodies of neutrophils: formation induced by cis-unsaturated fatty acids and mediated by protein kinase C. Journal of Cell Biology, 113, 137-146.

Xi, Y., \& Rocke, D. M. (2008). Baseline correction for NMR spectroscopic metabolomics data analysis. BMC Bioinformatics, 9, 324.

Zietkowski, D., Payne, G. S., Nagy, E., Mobberley, M. A., Ryder, T. A., \& Desouza, N. M. (2012). Comparison of NMR lipid profiles in mitotic arrest and apoptosis as indicators of paclitaxel resistance in cervical cell lines. Magnetic Resonance in Medicine, 68, 369-377. doi:10.1002/mrm.23265. 